\title{
Montagnier's New York project moves forward
}

The Governor of New York State, George Pataki, has pledged \$15 million towards the construction of Luc Montagnier's new HIV research Center at Queens College. The Salick Center projectnamed after Healthcare mogul, Bernard Salick who donated money to the operation last year-is now $\$ 9$ million short of its projected $\$ 30$ million target.

Ground-breaking for the Center will begin this July and the building is expected to be fully functional by 2000 . It will be dedicated to the development and clinical testing of subunit HIV vaccines aimed at boosting $\mathrm{T}$ cell immunity in infected patients. Montagnier also ducing protective immunity and is seeking to recruit "top immunologists" to join a new staff of 60 . Montagnier, who plans to develop vaccines capable of infor the health and joins the Queens College faculty next month, will present a major public lecture in May.

Pataki described the investment as a "far-sighted provision well-being of the people of New York state." In fact, Centers for Disease Control and Prevention figures released last month show that AIDS deaths in New York City dropped by 48 percent last year-seven peo-

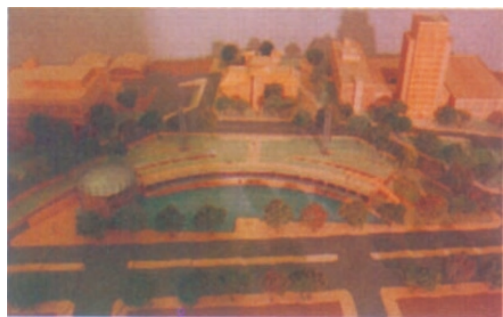

Architect's model of the Salick Center. the United Kingdom has also fallen by 44 percent to its lowest in six years. This decrease is again ascribed to the new compounds, which delay the progression from HIV to AIDS. However, the incidence of the disease is on the increase in Japan and China. record number of new AIDS patients in 1997, bringing the total to 1,684 and 3,357 HIV carriers. China, which has an ple died each day compared with 19 per day in 1995 . The decline is largely attributed to the new protease inhibitor drugs.

The number of AIDS cases reported in Japan reports a estimated 200,000 infected people, has reported a 70.7 percent increase in cases of HIV infection up to October last year.

Karen BirminghaM, NeW YorK

\section{Cancelled trial exposes Japanese research deficiencies}

Green Cross Corporation, a major pharmaceutical company and leading blood products manufacturer in Japan, announced last month that it is abandoning a proposed gene therapy trial on four HIV patients at Kumamoto University Medical School.

The cancellation of the trial is unsurprising to many: a 200-patient, Phase II study last year by Green Cross' American partner Chiron, yielded no positive efficacy data. What is surprising is the fact that this was to be only the second gene therapy experiment in Japan. This situation leads many to believe that the country fundamentally lacks the basis for research in gene therapy.

A Tokyo University professor says that the weakness arises from Japan's high dependence on US technology. "We would like to develop and use our own products, but there is no organization for ensuring the safety standards of vectors in Japan, which is why we cannot help but rely on AmeriCross trial was postponed last year because of safety concerns with a shipment of vectors from Chiron. Researchers at Tokyo University, who are currently awaiting approval of a gene therapy trial for kidney cancer, have also suffered a similar problem. Their program was seriously delayed last year when the US company providing the vector, Somatix Therapy, was acquired by Cell Genesys.

Even the safety guidelines for gene therapy-issued by Ministry of Health and Welcan technology," he says. In fact, the Green fare in 1995-have been criticized as being a mere translation of those in the United States (Nature Med. 1, 1233; 1995). Some researchers told Nature Medicine that the problem stems from government councils and committees that lack true "specialists" in the field, despite their responsibility for creating safety guidelines and assessing submissions for clinical trials.

There is added criticism of the approval procedure for clinical trials in general. The Japanese government is often reluctant to approve trials for new therapies unless they have been shown to be effective elsewhere.
"This makes the whole purpose of clinical trials meaningless," says Shuzo Matsushita, a professor at Kumamoto University, who was to have been responsible for the Green Cross HIV trial. To add insult to injury, the current system requires that informed consent be obtained from participating patients before the clinical trial approval is granted. "The patients [in the Green Cross trial] have waited for three years and all we could do was relay the data from the Phase II trial to them as an explanation for stopping the trial," adds Matsushita.

\section{Asako SAEgusa, TOKYo}

\section{Of Mice and Men}

Roger Short of the Royal Women's Hospital in Melbourne, Australia, has applied to the US National Institutes of Health for funding for what is perhaps one of the most conceptually bizarre experimental protocols in recent history: Short intends to produce human sperm in mice testes.

The idea comes from studies in which mice have produced mature rat sperm (Nature, 381, $418 ; 1996)$, and now Short wants to use this model as a potential treatment for human infertility. He says it may be possible to perform gene therapy on defective germ cells from human testicular biopsies, then transfer these corrected cells into mouse testes to examine whether normal spermatogenesis has been restored. "Repaired" cells would be returned from the mouse to the infertile patient. Any volunteers? K.B. 